\title{
Genetic Variation in Flammulina velutipes
}

\author{
Jong Bong Kim* and Ja In Jeong
}

Department of Medical Life Science, Catholic University of Daegu, Gyungsan 712-702, Korea

Received July 27, 2011 /Revised September 14, 2011 /Accepted September 16, 2011

\begin{abstract}
A genetic variation within 29 strains of $F$. velutipes was analyzed by internal transcribed spacer (ITS) sequence analysis and random amplified polymorphic DNA (RAPD). Seven hundred and twenty base pairs were sequenced during the analysis of the ITS region, but no significant variation was observed among the 29 strains of $F$. velutipes. Sixteen out of 40 random primers amplified polymorphic RAPD fragment patterns. The polymorphic levels of RAPD bands by some primers (OPA-2,4,3,9,10,20) were very high in all 29 strains, with 3,030 fragments ranging between 200 and 2,000 bp. Intraspecific genetic dissimilarity of the 29 strains was calculated to range from $3.3 \%$ to $45 \%$ by Nei-Li's method using these 3,030 RAPD bands. The genetic variation among Korean strains was relatively high, with dissimilarities ranging between $17 \%$ and $38.6 \%$. In the Neighbor-Joining analysis using the genetic dissimilarities based on RAPD, all 29 strains were classified into 5 clusters. Strains in each cluster showed specific characteristics according to their origin and strains. These results suggested that OPA and OPB primers could be used for developing molecular genetic markers and screening of unidentified (F. velutipes) strains.
\end{abstract}

Key words : Mushroom, genetic variation, genetic polymorphism, random amplified polymorphic DNA (RAPD), internal transcribed spacer (ITS), Flammulina velutipes

\section{서 론}

팽이버섯(Flammulina velutipes)은 Tricholomataceae과에 속 하는 담자균으로 늦가을부터 이른 봄에 걸쳐 발생하는 겨울버 섯으로 한국, 일본, 중국 등에서 가장 많이 선호하는 식용버섯 의 하나다.

식용 팽이버섯의 대부분은 자실체가 야생의 갈색이 아니라 육종에 의해 개발된 순백색이고 현재까지 우리나라의 대부분 농가에서 재배되고 있는 것들은 일본에서 개발 된 것들이다. 그러나 우리나라가 2002년 국제 식물 식품 종 보호조약 (International Union for the Protection of New Varieties of plants, UPOV)에 가입하였고, 2008년부터 팽이버섯이 품종보 호 대상에 해당됨에 따라 현재 이용되고 있는 외국 품종을 그대로 재배한다면 이용료를 지불해야 하므로 선호도가 높은 국산 팽이버섯의 개발이 절실하다[3,4].

신품종은 형태적, 생리적 특성의 구별성, 균일성이 분명해 야 하나 팽이버섯 품종들의 경우 재배환경에 따른 특성의 변 이가 커서 특이성을 뒷받침할 수 있는 분자 유전적 표지 개발 이 중요하다. 그러나 새로운 품종의 개발과 이의 평가의 바탕 이 될 수 있는 팽이버섯의 유전적 특성에 관한 연구는 많이 이루어져 있지 않다.

팽이버섯 자실체 색의 유전양식과 자실체와 연관된 분자마

\footnotetext{
*Corresponding author

Tel : +82-53-850-3775, Fax : +82-53-850-3727

E-mail : jbkim@cu.ac.kr
}

커[1,12], 팽이 수집 품종들에 대한 RAPD 분석[14], RAPD에 의한 단포자의 유전적 변이[13], 팽이버섯 발생에 따른 EST (expressed seguence tags) [9,25], genome의 크기와 핵형 $[10,20]$ 등이 보고된 바 있고, 현재 팽이버섯 유전체를 밝히고 자 하는 연구가 진행되고 있다.

그러나 팽이버섯은 세계적으로 200여 종류의 품종이 있지 만 품종들을 식별하고 이를 바탕으로 교배육종을 설계 혹은 품종평가를 할 수 있는 분자유전적 보고는 일부분에 불과하 다. 한편 유연관계를 밝히고 분자 마커를 개발하기 위한 방법 으로 RFLP (restriction fragment length polymorphism), CAPS (cleaved amplified polymorphic sequence), STS (sequence target site) 등 여러가지 방법을 이용하여 새로운 primer의 개발로 인하여 ITS (internally transcribed spacer), RAPD (random amplified polymorphic DNA) 등을 이용한 방법[23] 연구들이 지속적으로 이루어져 이에 따른 성과를 얻 고 있다[2,11,16,19].

이러한 점들과 관련하여 본 연구에서는 팽이버섯을 가장 많이 육종, 생산, 이용하고 있는 한국, 일본, 중국의 야생 팽이 버섯들과 상업용 육종 팽이버섯 등의 유전적 변이를 ITS 및 다양하게 개발된 primer들을 이용한 RAPD 방법으로 분석하 여 지역 간 혹은 상업용 품종간의 유전적 유사도와 그 특성을 밝히고자 하였다. 또한 새로운 품종 개발에 활용할 수 있고 유전적 정보와 분자 유전마커로서의 가능성을 평가하고자 하 였다. 


\section{재료 및 방법}

\section{실험 균주}

본 실험에서 사용된 팽이버섯(Flammulina velutipes) 균주 29 종은 한국, 일본, 중국의 야생 갈색 균주(한국 10 종, 일본 2 종, 중국 2종)와 이미 육종된 백색균주(한국 2종, 일본 8 종, 중국 5 종)등 총 29종의 균주를 각각 인천대학교, (주)그린피스, 농업 기술원에서 분양받아 ITS와 PCR-RAPD 분석을 위한 실험 재 료로 사용되었다(Table 1).

\section{균주의 배양}

팽이버섯 균주 배양은 PDA (Difco USA) 배지를 이용하였 으며, $39 \mathrm{~g} / 1$ 의 용량으로 조제하여, $121^{\circ} \mathrm{C} 15$ 분간 멸균한 뒤 clean bench에서 $90 \mathrm{~mm}$ petri dish에 $20 \mathrm{ml}$ 씩 분주하여 완전 히 식힌 뒤 medium으로 사용하였다. 또한 균주의 계대 배양 시 $25^{\circ} \mathrm{C}$ 의 incubator에서 20 일간 배양하여 본 실험에 사용하
였다.

\section{Genomic DNA 추출}

Genomic DNA의 추출을 위해 PDA 배지에서 20 일에서 23 일간 배양한 균사를 사용하였으며, DNA 추출법은 Lee 등[15] 의 방법을 약간 변형하여 사용하였다.

배양한 균사를 0.2-1 g 채취하여 mortar에 넣고 liquid nitrogen으로 급 냉 시켜 냉동상태에서 미세하게 마쇄한 다음 lysis buffer [50 mM Tris-HCl (pH 7.2), 50 mM EDTA (pH 8.0), $3 \% \mathrm{SDS}, 1 \%$ 2-Mercaptoethanol] $500 \mu 1$ 를 넣어 잘 섞고, $65^{\circ} \mathrm{C}$ Water bath에서 1시간 동안 반응시킨 후 $12,000 \mathrm{rpm}$ (Effendorf 5415 centrifuge, German) $4^{\circ} \mathrm{C}$ 에서 15 분간 원심분 리 후 상등액만 취하였다. 여기에 동량의 phenol:chloroform:isoamylalcohol (25:24:1) 용액을 첨가 $15,000 \mathrm{rpm}$ 에서 5 분간 원심분리하여 새로운 tube에 상등액만 취하였다. DNA 가 녹아있는 상등액에 2배의 absolute ethanol을 넣고 20-30분

Table 1 . The source and locality of strains

\begin{tabular}{|c|c|c|c|c|c|c|c|c|}
\hline \multirow[t]{2}{*}{ Strain no. } & \multirow[t]{2}{*}{ Species } & \multirow[t]{2}{*}{ Sample } & \multirow[t]{2}{*}{ Origin } & \multicolumn{2}{|c|}{ Type of Pileus } & \multicolumn{2}{|c|}{ Type of stipe } & \multirow[t]{2}{*}{ Type } \\
\hline & & & & Color & Size & Color & Size & \\
\hline 01 & $F$. velutipes & KB-1 & Korea & Brown & Small & Brown & Thick & Wild type \\
\hline 02 & $F$. velutipes & KB-2 & Korea & Brown & Small & Brown & Thick & Wild type \\
\hline 03 & $F$. velutipes & KB-3 & Korea & Brown & Small & Brown & Thin & Wild type \\
\hline 04 & $F$. velutipes & KB-4 & Korea & Brown & Small & Brown & Thin & Wild type \\
\hline 05 & $F$. velutipes & KB-5 & Korea & Brown & Small & D.Brown & Thick & Wild type \\
\hline 06 & $F$. velutipes & KB-6 & Korea & Brown & Small & D.Brown & Thick & Wild type \\
\hline 07 & $F$. velutipes & KB-7 & Korea & Brown & Small & D. Brown & Thin & Wild type \\
\hline 08 & $F$. velutipes & KB-8 & Korea & Brown & Spread & L. Brown & Thin & Wild type \\
\hline 09 & $F$. velutipes & KW-2 & Korea & White & Large & White & Thick & Variety Breeding \\
\hline 10 & $F$. velutipes & KB-9 & Korea & Brown & Spread & L. Brown & Thin & Wild type \\
\hline 11 & $F$. velutipes & KB-10 & Korea & Brown & Spread & L. Brown & Thin & Wild type \\
\hline 12 & $F$. velutipes & KW-1 & Korea & White & Large & White & Thin & Variety Breeding \\
\hline 13 & $F$. velutipes & JB-1 & Japan & Brown & Small & White & Thick & Wild type \\
\hline 14 & $F$. velutipes & JB-2 & Japan & Brown & Small & White & Thick & Wild type \\
\hline 15 & $F$. velutipes & JW-1 & Japan & White & Small & White & Thick & Variety Breeding \\
\hline 16 & $F$. velutipes & JW-2 & Japan & White & Small & White & Thick & Variety Breeding \\
\hline 17 & $F$. velutipes & JW-3 & Japan & White & Small & White & Thick & Variety Breeding \\
\hline 18 & $F$. velutipes & JW-4 & Japan & White & Large & White & Thick & Variety Breeding \\
\hline 19 & $F$. velutipes & JW-5 & Japan & White & Large & White & Thick & Variety Breeding \\
\hline 20 & $F$. velutipes & JW-6 & Japan & White & Large & White & Thick & Variety Breeding \\
\hline 21 & $F$. velutipes & JW-7 & Japan & White & Large & White & Thin & Variety Breeding \\
\hline 22 & $F$. velutipes & JW-8 & Japan & White & Small & White & Thin & Variety Breeding \\
\hline 23 & $F$. velutipes & CB-1 & China & Brown & Small & Brown & Thin & Wild type \\
\hline 24 & $F$. velutipes & CB-2 & China & Brown & Small & Brown & Thin & Wild type \\
\hline 25 & $F$. velutipes & CW-1 & China & White & Large & White & Thick & Variety Breeding \\
\hline 26 & $F$. velutipes & CW-2 & China & White & Small & White & Thick & Variety Breeding \\
\hline 27 & $F$. velutipes & CW-3 & China & White & Small & White & Thick & Variety Breeding \\
\hline 28 & $F$. velutipes & CW-4 & China & White & Small & White & Thick & Variety Breeding \\
\hline 29 & $F$. velutipes & CW-5 & China & White & Large & White & Thick & Variety Breeding \\
\hline
\end{tabular}

D. Brown: Dark Brown

L. Brown: Light Brown 
간 $\mathrm{DNA}$ 를 침전시켜 $15,000 \mathrm{rpm}$ 에서 5 분간 원심분리 하였다.

$\mathrm{DNA}$ 함량을 측정하기 위해 $\mathrm{DNA}$ 를 100 배 희석하여 spectrophotometer-(Shimadzu UV-VIS1201, Japan)로 $260 \mathrm{~nm}$ 와 $280 \mathrm{~nm}$ 에서 흡광도(OD)를 측정하여 농도를 계산하고, $\mathrm{PCR}$ 을 위한 template DNA로 사용하였다.

\section{ITS primer와 증폭}

ITS 염기서열을 분석하기 위하여 증폭한 부분은 White 등 [22]에 의해 보고된 fungi의 ITS영역 즉 partial $16 \mathrm{~S}$ ribosomal DNA, complete ITSI, 5.85 ribosomal DNA 및 partial 285 ribosomal DNA였다. 증폭을 위해 ITSP1, ITSP2, ITSP3, ITSP4 primer들을 사용하였다(Fig. 1). 증폭은 Bioneer PCR kit를 사 용하였다. 본 실험은 MJ Research PTC 150 minicycler에서 수행하였으며 thermal cycle의 program은 primer ITSP 1과

2, ITSP3과 ITSP4를 달리하여 사용하여 반응시켰다.

ITSP 1과 2와 $\mathrm{PCR}$ 반응 조건은 template $\mathrm{DNA}$ 변형을 위해 $94^{\circ} \mathrm{C}$ 에서 30 초간 denature, $50^{\circ} \mathrm{C}$ 에서 30 초 annealing, $72^{\circ} \mathrm{C}$ 에 서 extension을 1 분씩 처리하여 $\mathrm{DNA}$ 를 증폭시키는 것을 1 cycle로 하여 40 cycle로 수행하였다. ITSP3과 ITSP4 primer를 이용한 PCR 반응은 $94^{\circ} \mathrm{C}$ 에서 30 초간 변성시키고, $50^{\circ} \mathrm{C}$ 에서 30 초간 annealing, $72^{\circ} \mathrm{C}$ 에서 1 분간 extension 것을 1 cycle로 하여 40 cycle로 수행하였다.

\section{PCR product의 정제 및 ITS 염기서열 분석}

ITS I 영역의 PCR 산물은 전기영동하여 나타나는 DNA band를 확인한 후, QIA-quick PCR purification kit (Qiagen Inc., USA)를 이용하여 정제하였다.

정제된 PCR산물을 이용하여 Perkin-Elmer applied biosystems ABI 377A (Perkin-Elmer Co.,USA)를 이용하여 PRISM Dye Dideoxi Terminator Cycle Sequencing로 분석하 였다[7,8,20]. 얻어진 염기서열을 Gene Bank 데이터베이스에 등록된 것들과 상동성을 비교하였다.

염기서열은 Sequencher (Gene codes Co., USA), Clustal X 를 이용하여 alignment 시킨 후, 최종 세부 정열은 수작업으로
보정하였다.

\section{RAPD primer와 PCR}

본 연구의 PCR 실험 시 RAPD를 위해 사용한 primer는 식물과 버섯들에 대한 유전적 다양성 및 유연관계 분석에 활 용되는 상업용 kti primer (OPA 01 20, OPB 01 20) (Operon Technologies, USA)를 사용하였다. code name과 sequence $\left(5^{\prime}\right.$ to $\left.3^{\prime}\right)$ 는 Table 2 에 나타내었으며, $\mathrm{G}+\mathrm{C}$ 의 함량은 $60-70 \%$ 이었다.

PCR을 위한 reaction mixture의 조성은 Bioneer PCR kit 를 사용하였다. PreMix kit에 genomic DNA $1.0 \mu \mathrm{l}$, primer $1.0 \mu \mathrm{l}$ 를 넣고, 전체 반응 용액이 $20 \mu 1$ 가 되도록 3차 증류수를 첨가하였다.

본 실험의 RAPD 증폭반응은 MJ Reserch PTC 150 minicycler에서 thermal cycle의 program은 Park 등[18]의 방법에 따라 수행하였다. Template DNA 변형을 위해 $94^{\circ} \mathrm{C}$ 에서 3 분 간 predenaturation 한 다음, $94^{\circ} \mathrm{C} 30$ 초간 denaturation, $40^{\circ} \mathrm{C}$ 에서 1 분간 annealing, $72^{\circ} \mathrm{C}$ 에서 elongation 을 5 분씩 처리하 여 $\mathrm{DNA}$ 를 증폭시키는 것을 $1 \mathrm{Cycle}$ 로 하였으며, 이 실험에서 는 45 cycle로 수행하였다. DNA 증폭이 끝난 후 최종적인 합 성을 위해 $72^{\circ} \mathrm{C}$ 에서 5 분간 안정화한 다음, $4^{\circ} \mathrm{C}$ 에서 보관 사용 하였다. 이때 각각의 primer에 대한 상기의 $\mathrm{PCR}$ 과정을 통한 screening을 실시하여, 선택된 primer 별로 3회 이상의 반복실 험을 수행하여 재현성이 뚜렸한 것만을 유용한 primer로 결정 하였다.

$\mathrm{RAPD}$ 를 수행한 PCR product는 $5 \mathrm{ng} / 100 \mathrm{ml}$ 의 농도로 ethidium bromide를 첨가한 $1.2 \%$ agarose gel (SIGMA, USA) 에서 1x TAE buffer에서 $50 \mathrm{mV}$ 로 전기영동 하였으며, $\mathrm{UV}$ 상에서 나타나는 DNA band를 확인하였다.

\section{Data 분석}

RAPD 결과, 반응이 나타난 16 개의 primer에서 다형성이 인정되는 3,030 개의 band를 발견하였다. 먼저 각 band를 하나 의 형질로 취급하여 코드화하였으며[20,22], 그리고 전체 코드

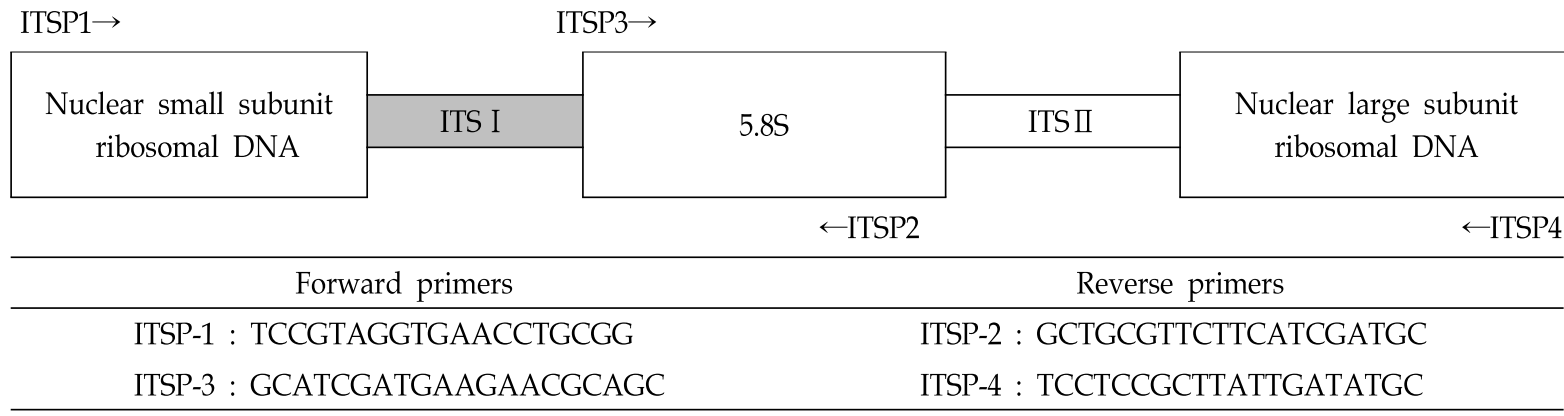

Fig. 1. Locations and sequences of primers for the amplification and sequencing. ITS primers were those designed by White et al [22]. 
Table 2. The list of primers used of RAPD analysis

\begin{tabular}{|c|c|c|c|}
\hline No. of primer & Sequence $\left(5^{\prime}\right.$ to $\left.3^{\prime}\right)$ & No. of primer & Sequence $\left(5^{\prime}\right.$ to $\left.3^{\prime}\right)$ \\
\hline OPA-1 & CAGGCCCTTC & *OPB-1 & GTTTCGCTCC \\
\hline *OPA-2 & TGCCGAGCTG & OPB-2 & TGATCCCTGG \\
\hline *OPA-3 & AGTCAGCCAG & OPB-3 & CATCCCCCTG \\
\hline *OPA -4 & AATCGGGCTG & OPB-4 & GGACTGGAGT \\
\hline *OPA-5 & AGGGGTCTTG & OPB-5 & TGCGCCCTTC \\
\hline OPA-6 & GGTCCCTGAC & OPB-6 & TGCTCTGCCC \\
\hline OPA-7 & GAAACGGGTG & *OPB-7 & GGTGACGCAG \\
\hline *OPA-8 & GTGACGTAGG & *OPB-8 & GTCCACACGG \\
\hline *OPA-9 & GGGTAACGCC & OPB-9 & TGGGGGACTC \\
\hline *OPA-10 & GTGATCGCAG & *OPB-10 & CTGCTGGGAC \\
\hline *OPA-11 & CAATCGCCGT & OPB-11 & GTAGACCCGT \\
\hline OPA-12 & TCGGCGATAG & OPB-12 & CCTTGACGCA \\
\hline OPA-13 & CAGCACCCAC & OPB-13 & TTCCCCCGCT \\
\hline OPA-14 & ACTGTGCTGG & *OPB-14 & TCCGCTCTGG \\
\hline OPA-15 & TTCCGAACCC & OPB-15 & GGAGGGTGTT \\
\hline *OPA-16 & AGCCAGCGAA & OPB-16 & TTTGCCCGGT \\
\hline OPA-17 & GACCGCTTGT & OPB-17 & AGGGAACGAG \\
\hline OPA-18 & AGGTGACCGT & OPB-18 & CCACAGCAGT \\
\hline *OPA-19 & CAAACGTCGG & OPB-19 & ACCCCCGAAG \\
\hline *OPA-20 & GTTGCGATCC & OPB-20 & GGACCCTTAC \\
\hline
\end{tabular}

*Reaction primer

화한 자료를 바탕으로 자료행렬을 작성하였다. 분지도는 UPGMA (unweighted pair-group method, arithmetic average method) 방법을 사용하였고, phylogenetic analysis에서 PAUP 4.02b version [21]을 사용하여 parsimony analysis를 실시하였으며, 분석방법으로는 Heurestic search를 이용하였 다. 이에 따른 option으로 ACCTRAN, MULPARS 및 TBR을 이용하였다. 또한 Nei [17]의 유전적 거리지수를 다소 변형한 $\mathrm{Nei}-\mathrm{Li}$ 의 거리지수를 이용하여 상사도 행렬을 도출하였다. 도 출된 자료행렬에 따라 산출된 유전적 유사도를 기초로 하여 neighbour joining tree $(\mathrm{NJ})$ 를 작성하였다[20]. 그리고 종간의
유전적 유사도 계수(similarity coefficient)는 Sneath와 Sokal [21]의 방법에 따라 구하였다. 또한 각 분계도의 지지정도는 jack-knifing [5], bootstrap [6]을 이용하여 분석하였다. 이러한 분석방법은 1,000 회 반복 실시하였다.

\section{결 과}

ITS 염기서열

Primer ITS 1, 2, 3, 4를 이용한 ITS 염기서열 분석한 결과 전체 720 개의 염기서열을 확인하였다(Table 3). 29개의 품종

Table 3. ITS sequence of $F$. velutipes

\begin{tabular}{ccccccc}
\hline NO & \multicolumn{2}{c}{ Base sequence } & & & & \\
\hline 1 & tcattaatga & acttgaact & gcttgtggct & cttgggctgt & tgctgacgag & gaccttcacg \\
61 & ggttcttcgt & acgtgcacgt & ctggggttgc & agctttcttc & gtccacctgt & gcacactctg \\
121 & taggtctgga & taccccattg & gaagggtgcg & cttttgcgc & tccetttgcc & ttccaggcct \\
181 & atgtcttaca & aacactatag & tatgtaacga & atgtcattga & ttattggact & tcactgtcct \\
241 & ttaaactaaa & tacaactttc & aacaacggat & ctctggctc & tcgcatcgat & gaagaacgca \\
301 & gcgaaatgcg & ataactaatg & tgaattgcag & aattcagtga & atcatcgagt & ctttgaacgc \\
361 & accttgcgcc & ctttggtact & ccgaagggca & tgcctgtttg & agtgtcagta & acttctcaac \\
421 & ctccctcact & ttgttgtgag & ctggcggatt & ggatgtgggg & gcttgctgga & ccttatcttt \\
481 & gggttcagct & cccctgaaat & gcattagcag & aaaccgttac & ctttggcgc & gctgcagctg \\
541 & tgataattat & ctacggctat & ggctgggctg & actgtgttgt & agcgctcgtc & tcgtctctga \\
601 & agtggtttcg & ccttagttgg & tgcttcctt & tgccttctct & ctcacgagag & atacctgtga \\
661 & cgcgagtgcg & cgggctattc & cgcttctaac & cgtcccttg & tgggacaaac & tattgaccat \\
\hline
\end{tabular}

This ITS contained partial 16S ribosomal DNA, complete ITS1, 5.8S ribosomal DNA and ITS2, and partial 28S ribosomal DNA. The length of this ITS sequence was 720 base pairs 
모두 동일하였으며, 이는 Genebank에 수록된 것[24]과 동일하 였다.

\section{RAPD}

29 개의 팽이품종들을 40 개의 primer를 이용하여 RAPD 분 석을 한결과 모든 품종에 반응들이 나타내었고 3 번의 반복실 험을 통하여 재현성이 확인된 것은 전체 40 개 중 16 종류의 primer였다(Table 2). 그 중 특히 polymeric band의 빈도가 높아 유전적 다양성을 잘 나타낸 primer들은 OPA-2,4,3,9, 10,20 이었다.

$\mathrm{PCR}$ 에 의하여 증폭된 band들은 $400 \mathrm{bp}$ 에서 $2,000 \mathrm{bp}$ 사이 의 구간에 분포하고 있었으며 primer에 따라서 8 16개의 band들이 나타내었다. 특히 primer OPA 3과 20을 이용한 $\mathrm{RAPD}$ 분석결과를 보면 일본과 중국품종의 JW1 7과 CB 1-2, CW 1-5에서 band들이 500 1,600 bp 사이에 유사하게 나타나 지만 한국의 야생종 KB 1 10들은 200 2,000 bp에서 매우 다양 하게 나타냈다(Fig. 2). 그러나 OPA-2, 9, 10과 OPB-7들을 이용 한 경우 band 분포가 모든 품종간에 다양성이 매우 컸다(Fig. 3). 또한 RAPD band 를 바탕으로 팽이버섯 형태 특징과 비교 할 때 일본, 중국, 한국 백색팽이버섯(JW, $\mathrm{CW}, \mathrm{KW})$ 그룹은 갓, 대의 형태가 일률적인 반면 특히 한국산 야생팽이 $(\mathrm{KB})$ 그 룹은 형태가 다양하였다(Table 1). 이는 RAPD band 분석에서 일본, 중국, 한국 백색팽이 그룹 band의 분포 범위가 좁고, 비슷한 양상을 띄었으며, 한국 야생팽이 그룹의 경우 band
분포 범위가 보다 넓고 다양하게 표현되었다(Fig. 2).

16 개의 random primer로부터 자료분석을 위한 3,030 개 의 scrabble RAPD band들을 marker로하여 Nei-Li's의 방법을 이 용한 비유사도 지수행렬을 조사한 결과(Table 4)

종내 유전적 변이는 $3.3 \sim 45 \%$ 로 나타났다. 종내 가장 낮은 변이는 CB-1, CB-2 중국산 야생품종들로 행렬도에 나타난 비 유사도지수는 3.3\%였으며, 가장 높은 변이는 KB-10와 JW-6로 $45 \%$ 였다.

한국산 야생팽이인 KB-1 10 품종간 비유사도는 17 38.6\% 로 나타났다. 한국산 야생팽이(KB)를 기준으로 일본산 야생팽 이(JB), 일본산 백색팽이(JW)의 비유사도지수는 각각 $23 ~ 42 \%$, $30 \sim 5 \%$ 로 나타났으며, 중국산 야생팽이(CB)와 백색팽이 $(\mathrm{CW})$ 는 각각 $25 \sim 38 \%, 27 \sim 3 \%$ 여서 한국산 야생팽이나 일본 산 백색팽이는 품종에 따라 다른 종에 가까울 정도로 분화되 었음을 알 수 있었다.

일본산 백색팽이(JW)는 종내 비유사도지수는 $4 \sim 20 \%$ 로 나 타났고, 일본산 백색팽이(JW)와 중국산 백색팽이 $(\mathrm{CW})$ 들 간의 비유사도지수는 4 20\%로 나타났다. 특히 CW-2 5와 JW-7 8 간의 비유사도가 $4 \sim 10 \%$ 로 국가별 품종간의 가장 낮은 유전적 변이도가 나타났다.

Band의 변이에 기초하여 neighbor-joining tree $(\mathrm{NJ})$ 분석결 과 5개의 cluster를 형성하였다(Fig. 4). 각 cluster 마다 국가, 지역, 품종간의 구분을 볼 수 있었다. cluster I 의 경우 69/69 jacknife/bootstrap 지지도를 나타났으며, 특히 KB-1, KB-3는
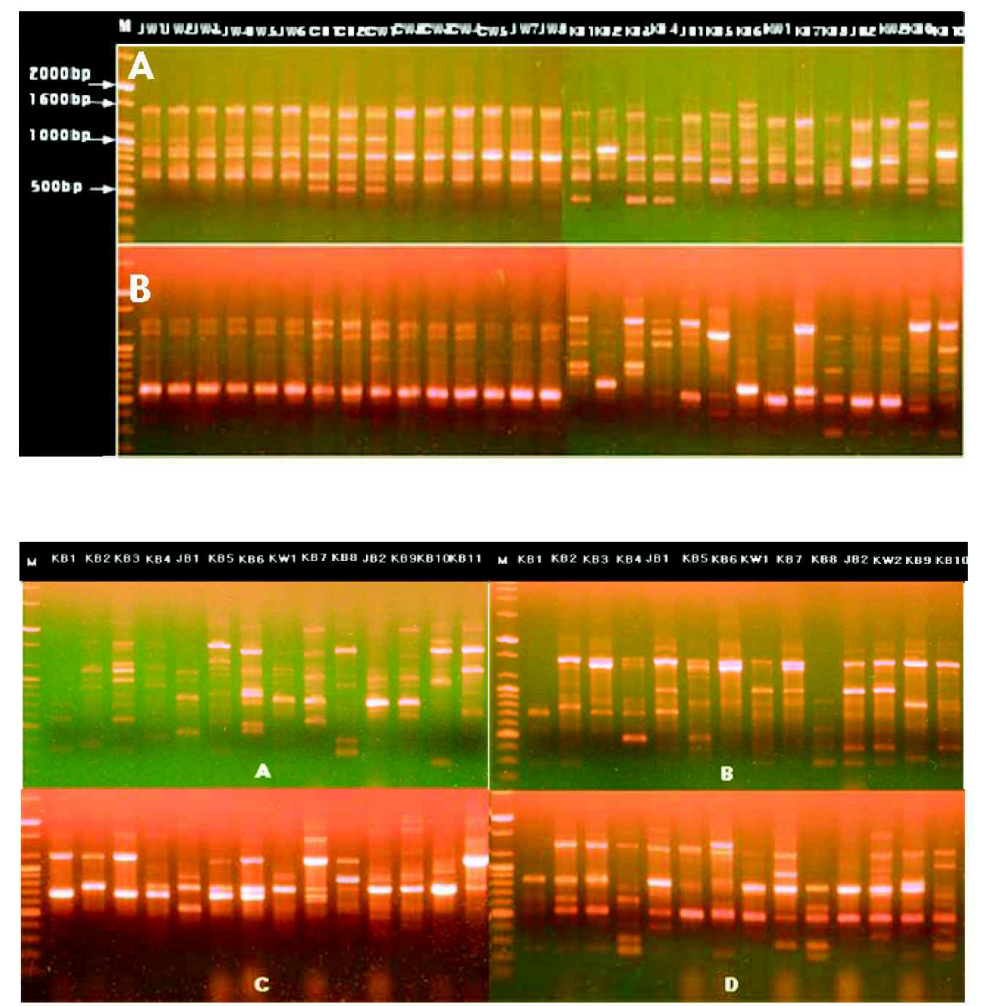

Fig. 2. Electrophoretic patterns of RAPD using primer OPA-3 and OPA-20. The patterns of Japan and China strains showed no variation but patterns of Korean strain were varied. A: Amplified by OPA-3, B: Amplified by OPA-20, M: $1 \mathrm{~kb}$ ladder marker.

Fig. 3. Electrophoretic patterns of RAPD using primer OPA-2, 9, 10 and OPB-7 were very varied depending on strains. A: OPA-2, B: OPA-9, C: OPA-10, D: OPB-7, M: 1 kb DNA Ladder. 
Table 4. Genetic dissimilarity matrix calculated by Nei-Li's genetic distance coefficient based on RAPD

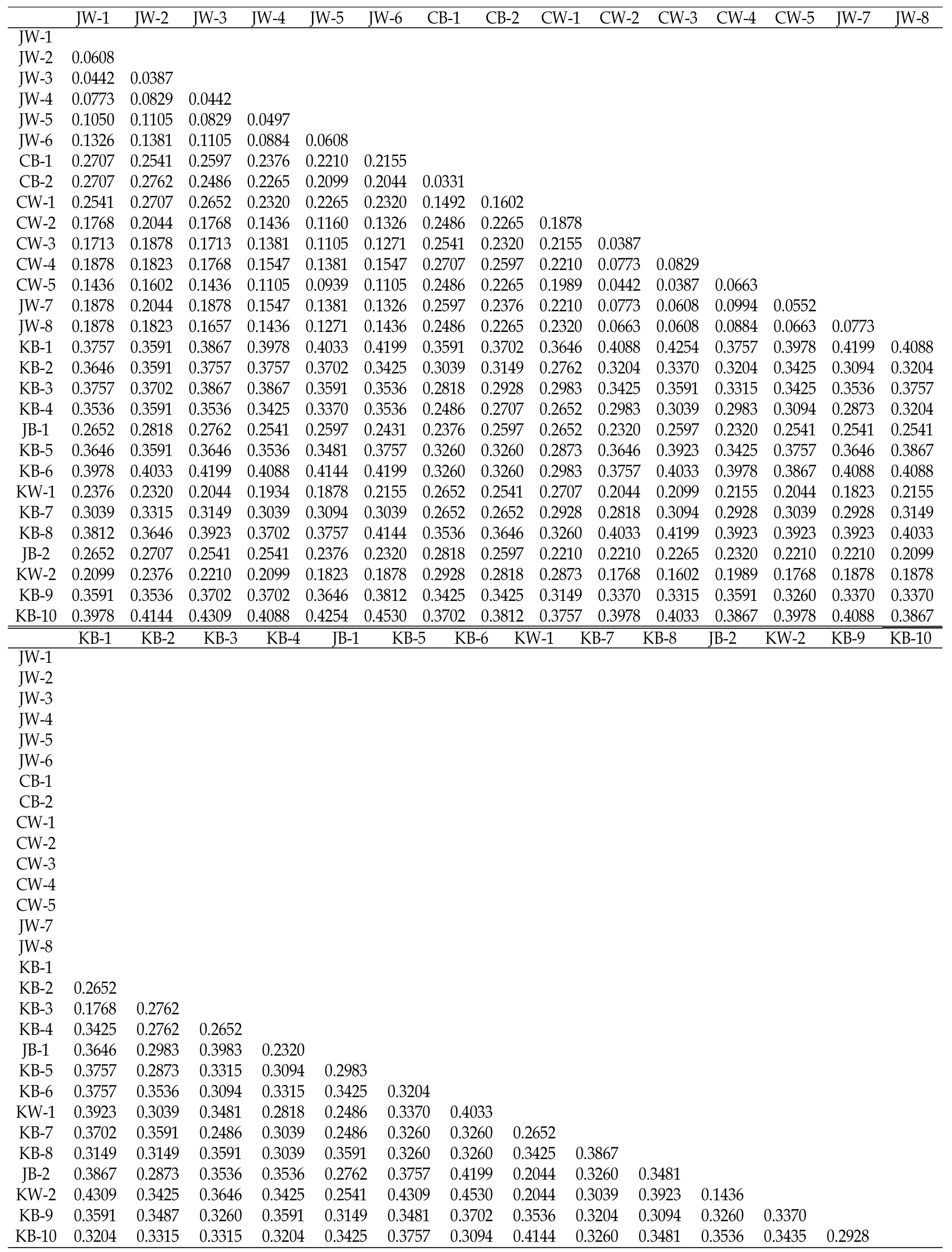




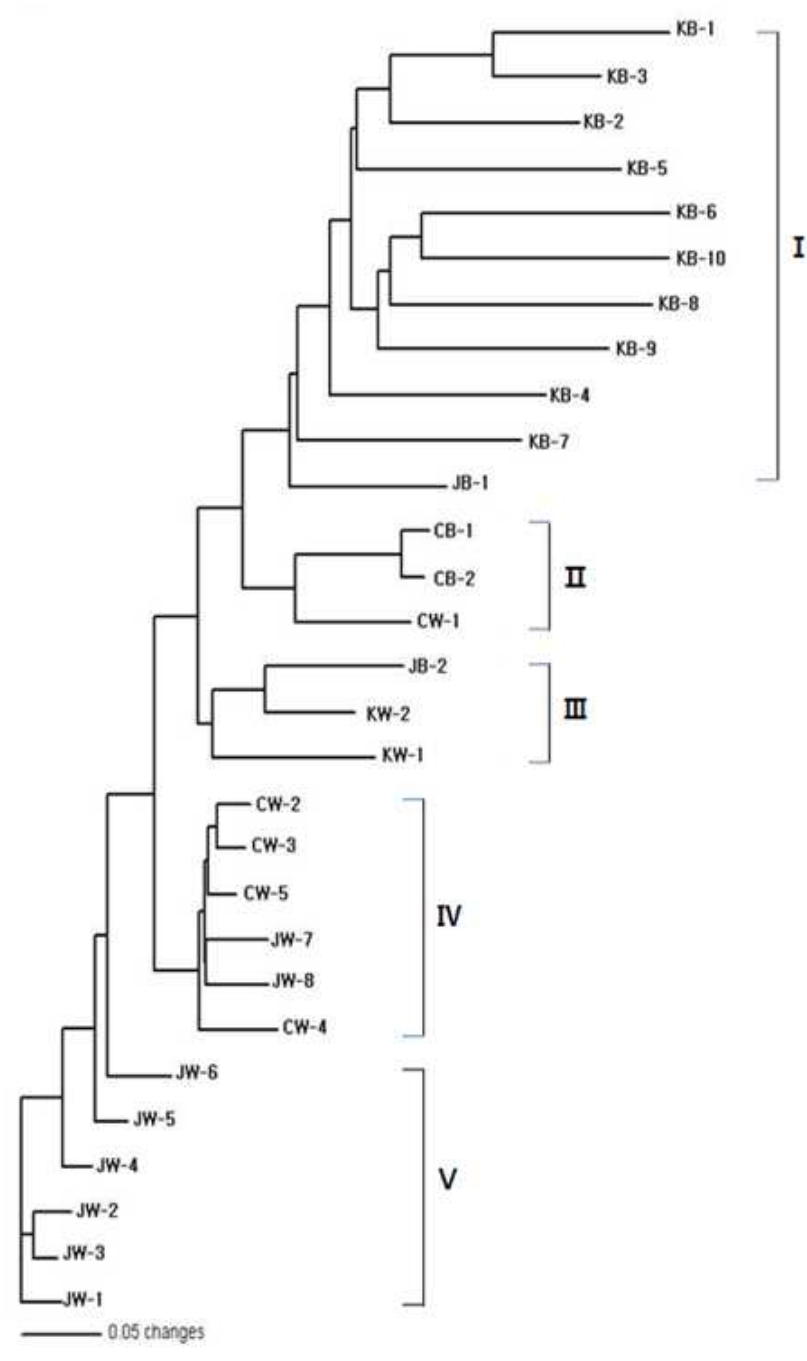

Fig. 4. The phylogenetic tree based on RAPD result of $F$. velutipes by neigbor-joining $(\mathrm{NJ})$ method.

97/95 jacknife/bootstrap의 지지도를 얻었다. Cluster 프는 중 국산 야생품종 CB-1, CB-2 100/100 jacknife/bootstrap 지지도 를 나타내고 있다. cluster III 한국산 백색품종 2개와 일본산 야생팽이가, cluster IV 중국산 백색팽이와 일본산 백색팽이가 97/93의 jacknife/bootstrap 지지도를 얻으며, 무리를 이루었 다. Cluster V 의 경우 일본산 백색팽이들로만 cluster를 이루 었다.

\section{고 찰}

본 연구결과 ITS 염기서열은 품종간의 유의적인 차이가 없 어 품종을 구별 할 수 있는분자 지표나 팽이 품종간의 유연관 계 분석을 위한 자료로서는 모두 적합하지 않다고 생각된다. 그러나 능이버섯이나 민자주방망이 버섯의 경우 본 연구에서 와 같이 동일 ITS 서열을 분석한 결과 민자주방망이 버섯은
지역간 품종의 비유사도가 1.58 11.4\%이고[16], 능이는 $1.8 \%$ 였던 것[11]과 비교하여보면 팽이버섯의 지역간, 품종간 ITS 염기서열의 높은 유사도의 원인은 분명치 않다. 백색종들의 경우는 각종의 모 품종이 유사한 것 들이 었을 것으로 보인다. 국가 등 지역간의 경우는 팽이버섯 ITS 염기서열의 특이성으 로 더 많은 분석을 해야 한다고 생각된다.

$\mathrm{RAPD}$ 의 경우 40 개의 primer들 중 16 개의 primer의 분석 대상이었던 29품종 모두에서 재현성이 뛰어난 band들이 나타 났다. 또한 primer들에 따라 band의 양상에 차이가 있어 OPA-2, 9, 10 등 2 4 종류의 primer들을 같이 사용 할 경우 모든 품종에 대하여 차별화된 밴드를 확인 할 수 있으므로 이들은 품종을 식별하는데 분자 maker로서의 이용이 가능하 다고 사료된다.

그러나 모든 대상 품종들에 대한 다양한 형태적, 생리적 분 석결과가 이루어져 있지 않아 이러한 형질들과 본 연구의 $\mathrm{RAPD}$ 에 의한 품종들의 band 양상과의 관계를 규명할 수 없 었다. 이를 위하여 각 품종들의 형태, 생리적 특성에 대한 추가 적 분석과 연구결과 등의 계량화가 요구 된다고 본다.

또한 교배 육종 시에 단핵균주를 사용해야 하고 단핵균주들 의 분자 유전적 특성이 다르다는 점[14]을 고려할 때 본 연구결 과에 사용한 균주들은 이핵균주들이므로 육종을 위해서 단포 자 균사의 RAPD 분석이 요구된다. 그리고 일본산 백색종 $(\mathrm{JW})$, 중국산 백색종 $(\mathrm{CW})$, 중국산 야생종 $(\mathrm{CB})$ 간의 band 의 패턴은 거의 유사하게 나타났다. 또한 중국 인공백색팽이 $(\mathrm{CW})$ 의 경우 일본산 인공백색팽이(JW)와 유전적 변이도는 $3 \sim 20 \%$ 차이가 났다. 이를 보면 대부분의 중국산 인공백색팽이 의 경우 일본산 인공백색팽이와 유전적 변이가 비교적 없었 다. 중국의 경우 육종 시 모균주를 일본산에 많이 의존하는 것으로 판단이 되며, 이미 육종기술이 많이 앞선 일본산 인공 팽이를 가져와 약간의 변형만 있었을 뿐 독립적인 개발이 의 심스러운 것으로 추정이 된다.

KB-1 10 한국산 야생종의 경우 band의 패턴 분석 결과 매 우 다양한 패턴으로 전개되는 것으로 보아 자연상태에서 유전 적 변이가 상당히 이루어져 온 것으로 보인다. 이는 팽이육종 의 근간이 되는 야생종 특히 한국 고유종의 팽이를 육종할 경우 다른 국가와 차별화될 수 있는 팽이를 육종할 가능성이 높을 것으로 판단된다.

유전적 비유사도 지수행렬의 종간 가장 낮은 것은 CB-1, CB-2 등의 중국산 야생팽이로 $3.3 \%$ 의 변이도를 나타냈다. 이 는 두 품종이 동일 종으로 판단 된다.

품종간 가장 높은 변이는 한국야생종 KB-10과 일본 백색종 $\mathrm{JW}-6$ 로 $45 \%$ 로 인위적인 육종으로 인해 종내의 변이를 넘어 종분화의 수준에 이르렀음을 보여 주었다.

일본산 백색팽이 $(\mathrm{JW})$ 와 한국산 야생종 $(\mathrm{KB})$ 과는 $30 ~ 45 \%$ 의 유전적 변이도를 보였다. 또한 중국산 야생팽이 $(\mathrm{CB})$ 와 $20 \sim 28 \%$ 의 변이도를 보였으며, 일본의 백색팽이는 한국과는 
유전적으로 많이 차이가 나 그들만의 독자적인 팽이를 육종한 것으로 보인다.

특히 한국산야생팽이의 경우 중국이나 일본의 야생 팽이 와는 유전적 거리가 멀게 나타났다. 이는 지리적 격리의 영 향을 어느정도 받은것으로 보인다. 한국에서 개발된 백색팽 이인 KW-1, KW-2의 경우 국산 야생팽이의 유전적 변이도는 $28 \sim 5 \%$ 차이가 나지만, 비교적 일본야생팽이(JW)와 변이도 는 14 $25 \%$ 의 차이를 나타내고 있고, 마찬가지로 일본산 백 색팽이와 $18 ~ 23 \%$ 로 나타났다. 이는 한국에서 육종된 KW-1,2가 한국산 팽이보다 일본산 야생, 백색팽이에 더 가 까운 것으로 보아 한국 팽이 육종이 비교적 독립적으로 종의 차이를 두는 것 같으나 일본산 팽이를 바탕으로 육종되는 것 으로 생각된다.

이상의 결과들로 RAPD 분석결과를 통하여 분자 유전적으 로 교배 육종의 과정, 신품종 평가를 위한 분자 유전적 기준 등으로의 활용이 가능하다고 본다. 또한 형태 생리적인 변이 와 특성들과 연관된 RAPD 특이성, 각 품종들의 단핵균주의 $\mathrm{RAPD}$ 양상 등의 추가적 연구가 이루어진다면 품종개발의 자 료로 활용 될 수 있다고 본다. KB-1 10 한국산 야생종의 경우 band 패턴 분석 결과 매우 다양한 패턴으로 전개되는 것으로 보아 자연상태에서 유전적 변이가 상당히 이루어져 온 것으로 보인다. 이는 팽이육종의 근간이 되는 야생종 특히 한국 고유 종의 팽이를 육종할 경우 다른 국가와 차별화될 수 있는 팽이 를 육종할 가능성이 높을 것으로 판단된다.

\section{감사의 글}

본 연구는 2010년 대구가톨릭대학교 지원에 의하여 수행되 었습니다. 아울러 팽이버섯 균주들을 제공해준 그린피스(주) 에 감사를 드립니다.

\section{References}

1. Byun, M. O., W. S. Kong, Y. H. Kim, C. H. You, D. Y. Cha, and D. H. Lee. 1996. Studies on the inheritance of fruitbody color in Flammulina velutipes. Korean J. Mycol. 24, 237-245.

2. Cho, K. H., S. Heo, J. H. Kim, I. S. Shim, S. E. Han, S. H. Kim, D. H Kim, and H. R. Kim. 2010. Analysis of genetic diversity of apple cultivars using RAPD and SSRL makers. Korean J. Breed Sci. 42, 525-533.

3. Chang, H. Y. 2008. SWOT analysis for direction of Korean mushroom industry. Korean J. Mushroom Sci. 6, 63-67.

4. Chang, H. Y., C. D. Goo, Y. S. Park, I. S. Ko, and Y. S. Kim. 2010. Approach on the multifunctionality of mushroom. Korean J. Mushroom Sci. 8, 1-5.

5. Farris, J. S., V. A. Albert, M. Kallersjo, D. Lipscomb, and A. G. Kluge. 1996. Parsimony jackknifing outperforms neighbor-joining. Cladistics 12, 99-124.

6. Felsenstein, J. 1985. Confidence limits on phylogenies: An approach using the bootstrap. J. Evolution 39, 783-791.

7. Lisa, A. W., R. G. Higuchi, S. Mark, A. E. Henry, A. Norman, and C. W. Allan. 1987. Length mutations in human mitochondrial DNA: direct sequencing of enzymatically amplified DNA. Nucleic Acids Res. 15, 529-541.

8. Hirashi, A. 1992. Direct automated sequencing of $16 \mathrm{~S}$ rDNA amplified by polymerase chain reaction from bacterial cultures without DNA purification. Lett. Appl. Microbiol. 15, 210-213.

9. Joh, J. H., K. Y. Kim, J. H. Lim, E. S. Son, H. R. Park, Y. J. Park, W. S. Kong, Y. B. Yoo, and C. S. Lee. 2009. Comparative analysis of expressed sequence tags from Flammulina velutipes at different developmental stages. J. Microbiol. Biotechnol. 19, 774-780.

10. Tanesaka, E., K. Kinugawa, K. Okabe, Y. Kitamura, M. Ogawa, and M. Yoshida. 2003. Electrophoretic Karyotype of Flammulina velutipes and its variation among monokaryotic progenies. Mycoscience 44, 67-69.

11. Kim, J. B. 2004. The base sequence of ITS and genetic variation in sarcodon aspratus. J. Life Sci. 14, 963-966.

12. Kong, W. S., C. H. You, Y. B. Yoo, G. H. Kim, and K. H. Kim. 2004. Molecular marker related to fruitbody color of Flammulina velutipes. Mycobiol. 32, 6-10.

13. Kong, W. S., D. H. Kim, Y. H. Kim, C. H. You, M. O. Byun, and K. H. Kim. 1997. Genetic variability of Flammulina velutipes monosporous isolates. Korean J. Mycol. 25, 111-120.

14. Kong, W. S., C. H. Yoo, D. Y. Cha, D. H. Kim, and K. H. Kim. 1997. Genetic relationship of Flammulina velutipes based on ribosomal DNA and RAPD analysis. RDA. J. Indus. Crop. Sci. 29, 28-40.

15. Lee, S. M. 1988. A rapid high yield mini-prep method for isolation of total genomic DNA from fungi. Fungal Genet. Newsl. 35, 23-24.

16. Lee, Y. S. 2004. A Studied on the genetic characteristics and component of Lepista nuda Ph. D. Thesis, catholic University of Dae gu, Dae gu, Korea.

17. Nei, M. 1972. Genetic distance between populations. Amer. Naturalist 106, 283-292.

18. Park, W. M., H. G. Ko, R. J. Park, K. S. Hong, and G. H. Kim. 1997. Differentiation of Lentinus edodes isolates in Korea by isozyme polymorphism and random amplified polymorphic DNA (RADP) analysis. Korean J. Mycol. 25, 176-190

19. Lim, S. Y., H. J. Choi, T. S. Ryu, T. R. Kwon, J. K. Choi, and J. K. Son. 2010. Analysis of major traits native Ginseng (Panax ginseng C. A. Meyer) collected from Poonggi area in Korea using DNA marker. Korean J. Crop. Sci. 55, 253-258.

20. Smith, L. M., J. Z. Sanders, R. J. Kaiser, P. Hughes, C. Dodd, C. R. Connell, C. Heiner, S. B. H. Kent, and L. E. Hood, 1986. Fluorescence detecition in automated DNA sequence analysis. Nature 321, 674-679.

21. Sneath, P. H. A., and R. R. Sokal. 1973. Numerical taxonomy. pp. 573, W. H. Freeman, San Francisco.

22. White, T. J., T. Bruns, S. Lee, and J. Taylor. 1990. Amplification and direct sequencing of fungal ribosomal RNA genes for phylogenetics. pp. 315-322, Academic Press Inc., Sandiego, California. 
23. Williams, J. G. K., A. R. Kubelik, K. J. Livak, J. A. Rafalski, and S. V. Tingey. 1990. DNA polymorphisms amplified by arbitrary primers and useful as genetic markers. Nucleic Acids Res. 18, 6531-6535.

24. Woo, J. R. and J. G. Kim. 2011. Flammuliana velutipes $18 \mathrm{~S}$ ribosomal RNA, internally transcribed spacer $1,5.8 \mathrm{~S}$ ribosomal RNA, internally transcribed spacer 2, $28 \mathrm{~S}$ ribosomal RNA, intergenic spacer 1 , and $5 S$ ribosomal RNA partial sequence. Genebank HQ660197.1.

25. Yamada, M., S. Sakuraba, K. Shibata, S. Inatomi, M. Okazaki, and M. Shimosaka. 2005. Cloning and characterization of a gene coding for a hydrophobin, Fv-hydl, specifically expressed during fruiting body development in the basidiomycete Flammulina velutipes. Appl. Microbiol. Biotechnol. 67, 240-246.

\section{초록 : 팽이버섯의 유전적 변이}

김종봉* $\cdot$ 정자인

(대구가톨릭대학교 의생명과학과)

ITS 염기서열과 RAPD를 이용하여 F. velutipes 29 개의 팽이버섯 품종 간의 유전적 변이를 분석하였다. ITS 부 위에서 $720 \mathrm{bp}$ 의 염기서열을 확인 하였으나 29개의 팽이품종간에 유의적인 차이가 없었다. RAPD 분석 결과 40 개의 random primer 중 다형성을 나타내는 primer는 16개였으며, 그 중 뚜렸한 다형성을 띄는 primer는 OPA-2,4,3,9,10,20 이었다. 이들 29개 품종에서 primer에 의해 증폭된 밴드는 모두 3,030개 였으며, DNA 단편의 크기는 200 2,000 bp 사이에 위치하였다. 또한 3,030개의 scrabble RAPD band들을 marker로 하여 Nei-Li's의 방 법을 이용한 비유사도 지수행렬을 조사한 결과 전체 29개 품종의 종내 유전적 변이는 $3.3 ~ 45 \%$ 였고, 특히 한국 야생팽이의 종내 유전적 변이도는 17 38.6\%로 품종 간 다형성을 확인하였다. RAPD 변이에 기초하여 neighbor-joining tree $(\mathrm{NJ})$ 분석에서는 5 개의 cluster로 구분되었으며, 각각의 cluster는 품종, 지역 적 특성을 나타내었 다. 본 연구 결과 $\mathrm{RAPD}$ 와 실험을 통해 확인된 $\mathrm{OPA}, \mathrm{OPB}$ primer의 경우 미확인 팽이품종들을 검색 하는데 분자 유전적 표지 maker로써 이용 할 수 있는 것으로 생각된다. 